\title{
The Impact of Spices on Vegetable Consumption: A Pilot Study
}

\author{
Zhaoping Li1, Michael Krak¹, Alona Zerlin¹, Lena K. Brahe1,3, Alexis Rheinwald-Jones1, \\ Gail Thames', Yanjun Zhang1, Chi-Hong Tseng'2, David Heber ${ }^{1}$ \\ ${ }^{1}$ Center for Human Nutrition, David Geffen School of Medicine, University of California, Los Angeles, CA, USA \\ ${ }^{2}$ Department of Medicine Statistical Core, David Geffen School of Medicine, University of California, LoS \\ Angeles, CA, USA \\ ${ }^{3}$ Department of Nutrition, Exercise and Sports, Faculty of Science, University of Copenhagen, Denmark \\ Email: zli@mednet.ucla.edu
}

Received 3 March 2015; accepted 23 March 2015; published 30 March 2015

Copyright (C) 2015 by authors and Scientific Research Publishing Inc.

This work is licensed under the Creative Commons Attribution International License (CC BY).

http://creativecommons.org/licenses/by/4.0/

(c) (7) Open Access

\section{Abstract}

This pilot study was conducted to evaluate the impact of spices added to broccoli, cauliflower, and spinach on amount and rate of vegetable consumption. Twenty overweight subjects who routinely ate less than three daily servings of vegetables were recruited. On six occasions, subjects were assigned in random order to eat broccoli, cauliflower, or spinach with or without added spices. Dishes were placed on a modified Universal Eating Monitor (UEM) that recorded rate of eating $(\mathrm{g} / \mathrm{sec})$, duration of eating $(\mathrm{min})$ and total amount consumed $(\mathrm{g})$. Total intake and duration of eating were increased significantly for broccoli with spices compared to plain broccoli, but there was no significant difference for cauliflower or spinach. No significant differences were noted in any of the visual analog scale (VAS) responses. This study suggests that adding spices may increase vegetable intake, but more studies in greater numbers of subjects are needed.

\section{Keywords}

Spice, Vegetable Intake, Universal Eating Monitor

\section{Introduction}

Increasing the consumption of fruit and vegetables is a key component of chronic disease prevention efforts and has been shown to reduce the risk of obesity and type 2 diabetes [1] [2]. Public health campaigns to increase the number of servings of fruit and vegetables eaten per day include the "Fruits and Veggies-More Matters" in the US, the UK's "5 A DAY” campaign, Australia’s "Go 2 and 5" and the French "10 parjour" program.

How to cite this paper: Li, Z., Krak, M., Zerlin, A., Brahe, L.K., Rheinwald-Jones, A., Thames, G., Zhang, Y.J., Tseng, C.-H. and Heber, D. (2015) The Impact of Spices on Vegetable Consumption: A Pilot Study. Food and Nutrition Sciences, 6, $437-444$. http://dx.doi.org/10.4236/fns.2015.64045 
Although increased fruit and vegetable consumption is associated with well-established health benefits, consumer and marketing studies have invariably shown that taste, as opposed to perceived nutrition or health value is the key motivator of food selection [3]-[5]. There is also evidence in the US population that health and taste are inversely perceived, so that emphasizing the health benefits of a food may actually discourage some people from choosing that food [6]. This observation may be especially relevant to cruciferous vegetables such as broccoli, where bitter taste deters consumption. The glucosinolates, which are primarily responsible for the bitter taste, are also implicated in the health advantages associated with the consumption of cruciferous vegetables [7]. The organo-sulfur class of compounds often have undesirable sensory characteristics and tend to be disliked as a natural defense mechanism against toxins [8] [9]. There is considerable evidence that one of the main determinants of food choice is liking [10], and taste is the main driver of liking [11]. Innate preferences for sweet taste and innate dislike of bitter taste (fear of alkaloid toxins) and sour taste (aversion towards acids) are determinants of early taste acceptance ([8] [9] [12] [13]).

This pilot study was conducted to determine the feasibility of evaluating the impact of spices added to vegetables including broccoli, cauliflower, and spinach on amount and rate of vegetable consumption under controlled conditions using a Universal Eating Monitor (UEM). Pre- and post-consumption testing of taste, appetite and mood was assessed using a computer-based Visual Analog Scale (VAS).

\section{Methods}

\subsection{Subjects}

A total of 87 subjects between 30 - 60 years of age with a body mass index (BMI) $\geq 25$ and $\leq 30$ were screened. Ten male and ten female overweight but otherwise healthy volunteers met the inclusion criteria were enrolled in the study. Subjects already eating more than three servings of vegetables per day were excluded at screening using a validated measure of portions in order to eliminate those already eating cruciferous vegetables or spinach regularly [14]. Subjects with a significant medical condition including a history of diabetes mellitus, or other serious medical condition, such as chronic hepatic or renal disease, bleeding disorder, congestive heart disease, chronic diarrhea disorders, myocardial infarction, coronary artery bypass graft, angioplasty within 6 months prior to screening, current diagnosis of uncontrolled hypertension (defined as systolic BP > $160 \mathrm{mmHg}$, diastolic BP > $95 \mathrm{mmHg}$ ), active or chronic gastrointestinal disorders (other than appendectomy), bulimia, anorexia, or endocrine diseases (except thyroid disease requiring medication) as indicated by medical history or routine physical examination were excluded, as were subjects reporting any of the following: allergies to spice or vegetable, current use of tobacco products, vigorous physical activity on a regular basis or unwillingness to comply with the study protocol. Subjects were screened by stratifying their level of restrained eating based on the ThreeFactor Eating Questionnaire (TFEQ) [15] [16] along with measures of food and drink preferences and allergies. To ensure large differences in restraint between groups, subjects were pre-selected depending on their score on the TFEQ cognitive restraint scale, with scores greater than two defined as high restraint (HR), and two or less defined as low restraint (LR) eaters. An equal number of male and female high and low restraint eaters were entered into the study. The study was approved by the University of California Los Angeles Institutional Review Board.

\subsection{Study Design}

This was a prospective randomized pilot study. Three different vegetables-broccoli, spinach, and cauliflowerwere tested. In the experimental groups, each vegetable was paired with its own custom blend of spices specifically formulated to maximize taste and assess the hedonic aspects of eating. The plain versions of each vegetable served as the respective controls. Subjects received a total of six different vegetable combinations spread out across the six study visits. The order in which each participant was presented with the spiced or plain version of each vegetable was randomized.

\subsection{Vegetable Test Procedure}

Vegetables with no spice added or with a customized spice mixture were prepared by professional chefs (McCormick and Company, Inc., Huntsville, MD) and were delivered to the UCLA Center for Human Nutrition frozen in individual packages. The ingredients of the preparations are listed in Table 1. 
Table 1. Vegetable preparations.

\begin{tabular}{|c|c|c|c|c|c|c|}
\hline \multirow{2}{*}{ Ingredients } & \multicolumn{2}{|c|}{$\begin{array}{c}\text { Broccoli florets blanched } \\
\text { (300 grams) }\end{array}$} & \multicolumn{2}{|c|}{$\begin{array}{c}\text { Cauliflower florets blanched } \\
\text { (300 grams) }\end{array}$} & \multicolumn{2}{|c|}{$\begin{array}{l}\text { Baby spinach leaves } \\
\text { (300 grams) }\end{array}$} \\
\hline & Control & Seasoned & Control & Seasoned & Control & Seasoned \\
\hline Extra virgin olive oil & 1.3 & 1.3 & 1.3 & 1.3 & 1.3 & 1.3 \\
\hline Salt & 0.25 & 0.25 & 0.25 & 0.25 & 0.25 & 0.25 \\
\hline Dill weed & & & & 0.12 & & \\
\hline Dried chervil & & & & & & 0.07 \\
\hline Dried chives & & & & & & 0.13 \\
\hline Garlic powder & & & & 0.1 & & 0.4 \\
\hline Granulated garlic & & 0.7 & & & & \\
\hline Granulated onion & & 0.7 & & & & \\
\hline \multicolumn{7}{|l|}{ Ground cinnamon } \\
\hline Onion powder & & & & 0.05 & & 0.4 \\
\hline \multicolumn{7}{|l|}{ Pumpkin pie spice } \\
\hline Pure ground black pepper & & 0.25 & & & & \\
\hline Shaker grind black pepper & & & & 0.05 & & \\
\hline Whole basil leaves & & 0.12 & & & & \\
\hline
\end{tabular}

The vegetables were prepared as follows:

\section{Broccoli and cauliflower:}

1) Heat a pot of water to boiling.

2) Cut the broccoli/cauliflower into bite-size florets.

3) Cook the broccoli/cauliflower in the boiling water for 6 minutes.

4) Remove the broccoli/cauliflower from the water and shock in an ice bath.

5) Once chilled, remove from ice water and drain broccoli/cauliflower well in a colander.

6) Season the broccoli/cauliflower with the seasoning mix (Table 1).

7) Once seasoned, place appropriate amount of broccoli/cauliflower into microwave safe container and freeze. Spinach:

1) To season spinach-place oil needed in stainless bowl, add spinach and $1 / 3$ of seasoning needed. Mix well by hand, tossing to coat spinach with seasoning and oil. Add another 1/3 of seasoning and toss well then add remaining seasoning and toss well. Place spinach into vacuum seal bags as flatly as possible.

2) Vacuum seal the bag and place it in the freezer.

3) Once frozen, place the desired amount in a microwave safe container and hold until ready to use.

Subjects were provided with a standard breakfast of bagel and string cheese and after 150 minutes were served the test vegetable with or without spices. The subjects were asked to test two different preparations from each vegetable but were not informed as to the differences between the two preparations. The vegetables were heated in a microwave three times for three minutes. They were first heated in the shipped package and then twice in the glass bowl from which subjects ate the vegetables. The vegetables were stirred to evenly disperse heat between each heating and were served at a measured temperature of $600^{\circ} \mathrm{C}\left(1400^{\circ} \mathrm{F}\right)$.

\subsection{Universal Eating Monitor}

Universal Eating Monitors integrate a hidden weighing apparatus with specialized data collection software to analyze human eating [17]. The present study utilized a UEM comprised of a Cubis MSU balance (Sartorius Balances, city) and Sussex Intake Pattern Monitor (SIPM) software. SIPM measured the weight of the plate at regular intervals from the balance hidden beneath the table on a mobile platform as the participant consumed the test dish. The UEM then generated eating curves intake (g) against time (sec). 
To survey ratings of appetite, mood, and taste before and after test meals, a Visual Display Unit (VDU) prompted subjects to record question-based responses on various 500 pixel horizontal lines anchored with the phrases "Not at all" and "Extremely". The specific attribute to be rated was presented as an appropriate question positioned above the line. Subjects were asked to mark the place along the line that best described their feelings towards that attribute by accurately positioning a vertical bar on the horizontal line. The vertical line was initially presented in the center of the horizontal line, and could then be dragged in the appropriate direction using the computer mouse. All ratings were scored automatically by the computer on a scale of zero (Not at all) to 500 (Extremely). The appetite and mood ratings were hunger, thirst, full, and friendly, jittery, happy, nauseous, clearheaded, energetic and relaxed. Sensory and hedonic ratings of the vegetables were for how sweet, sour, salty, pleasant, and bitter the participant found the vegetables. Ratings of mood and appetite were in the format of "How do you feel?", while ratings of the hedonic and sensory qualities of the food was phrased "Please rate the following property of the food $<$ food descriptor $>$ ”.

Subjects were presented with a tray containing one of the six different vegetable preparations served as a buffet in containers. First, subjects were instructed to take a mouthful of the food item when prompted by the computer, and to complete the sensory and hedonic ratings. They were then instructed to complete a set of mood and appetite ratings and to eat as much as they like of the food for that session. Serving portions were generous, and participants were instructed to call their experimenter if they ran short of food. Once they ate as much as they liked they completed a final set of mood and appetite ratings.

\subsection{Statistical Analysis}

Overall intake, meal duration (time from the signaled start of the meal to meal completion), and eating rate (total intake divided by meal duration) were compared between vegetables with and without spice mix using paired t-tests. Analysis of Variance (ANOVA) was used to compare rated appetite at key points (the start and end of test meals). The specific relationship between rated appetite (hunger, fullness, and pleasantness of the eaten food) and actual food intake within the test meal was assessed by determining individual best-fit quadratic functions for each subject's data and then contrasting the three coefficients from these best-fit functions between two meals. Statistical significance was considered at a threshold value of 0.05 .

\section{Results}

The demographic characteristics of the subjects are listed in Table 2. There was no statistical difference between high restraint and low restraint subjects in ethnicity, age, body weight or BMI. All subjects completed the study without any significant adverse events. Two subjects, one high restraint and one low restraint eater, were excluded from the study analysis due to dietary noncompliance. Data analysis was carried out on the remaining 18 subjects.

The consumption of broccoli was increased from $134.1 \pm 140.0$ to $212.5 \pm 155.3(p=0.001)$ when spice was added compared to plain broccoli for the overall group of 18 subjects. In addition, the duration of eating the broccoli ad lib was increased from $3.5 \pm 2.3 \mathrm{~min}$ to $4.5 \pm 2.2 \mathrm{~min}(p=0.01)$. The rate of eating broccoli was unchanged as the rate of eating plain broccoli was $0.7 \pm 0.43 \mathrm{gram} / \mathrm{sec}$ while it was $0.8 \pm 0.27$ gram/sec for broccoli with added spices $(p=0.246)$. There were no differences in the amounts of cauliflower or spinach consumed with or without spices or in the duration or rate of eating ad lib of cauliflower or spinach (Figure 1).

When results were examined in the high restraint versus low restraint eaters, it was clear that the differences in amount of broccoli eaten and duration of ad lib eating were driven by the subgroup of the high restraint eaters while there were no differences in amounts eaten or duration of eating in the low restraint eaters. The amount of broccoli consumed was significantly higher in the high restraint compared to the low restraint eater subgroups ( $p$ $=0.031$ ) (see Figure 2). High restraint eaters consumed 91\% more spiced broccoli $(p=0.004)$ than plain broccoli. In addition, the rate of eating broccoli with spices was 50\% greater than plain broccoli in the high restraint eaters $(p=0.012)$. The VAS measures of mood, appetite, and taste were not significantly different between plain vs. spice test meals with broccoli, cauliflower or spinach.

\section{Discussion}

Diets rich in vegetables and fruit are associated with lower rates of cancer and coronary heart disease [7] [18] 
Table 2. Subject demographics.

\begin{tabular}{lccc}
\hline & Total & High restraint & Low restraint \\
\hline Subject No. & 20 & 10 & 10 \\
Female & 10 & 5 & 5 \\
Male & 10 & 5 & 5 \\
Ethnicity & & & \\
Hispanic or Latino & $7(35 \%)$ & $4(40 \%)$ & $3(30 \%)$ \\
Not Hispanic or Latino & $13(65 \%)$ & $6(60 \%)$ & $7(70 \%)$ \\
Age (years), mean \pm SD & $40.45 \pm 7.27$ & $39.90 \pm 6.87(2.17)$ & $41 \pm 7.99(2.53)$ \\
Race, No. (\%) & & & \\
Asian & $2(10 \%)$ & 0 & $2(20 \%)$ \\
Black & 0 & 0 & 0 \\
White & $16(80 \%)$ & $9(90 \%)$ & $7(70 \%)$ \\
Other & $2(10 \%)$ & $1(10 \%)$ & $1(10 \%)$ \\
BMI (kg/m²), mean \pm SD & $27.38 \pm 1.63$ & $26.87 \pm 1.41$ & $27.89 \pm 1.75$ \\
Weight (kg), mean \pm SD & $80.83 \pm 9.97$ & $79.7 \pm 9.5$ & $81.96 \pm 10.80$ \\
\hline
\end{tabular}

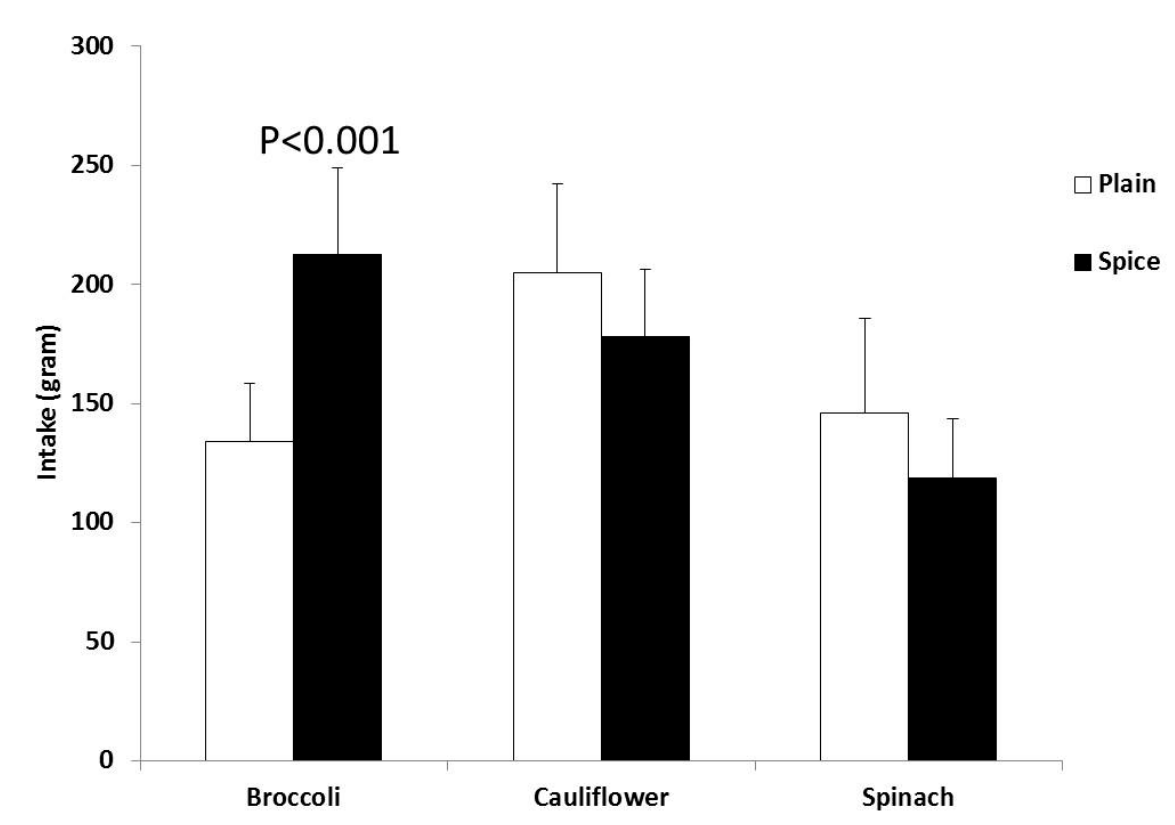

Figure 1. Total consumption of vegetables. $\square$ Plain vegetables without spice; $\mathbf{\square}$ vegetables with spice.

[19], but most Americans do not consume the five or more servings per day of fruits and vegetables recom mended by the government. Therefore, increasing the intake of healthy foods such as broccoli among restraint eaters by adding spices to improve acceptability and taste could be a useful strategy for increasing consumption of vegetables containing phytochemicals with bitter tastes.

Sensory-specific satiety (SSS) refers to the decrease of pleasure derived from a food during eating and it is established that the persistence of a taste tends to terminate eating behavior. SSS is specific to a particular food such as broccoli and is not affected by the ad libitum consumption of other foods with different sensory characteristics regardless of the order in which the other foods are presented. Once reached, SSS is thus not subject to dishabituation during a meal [20]. In our study, the duration of eating was increased with added spices, suggest- 


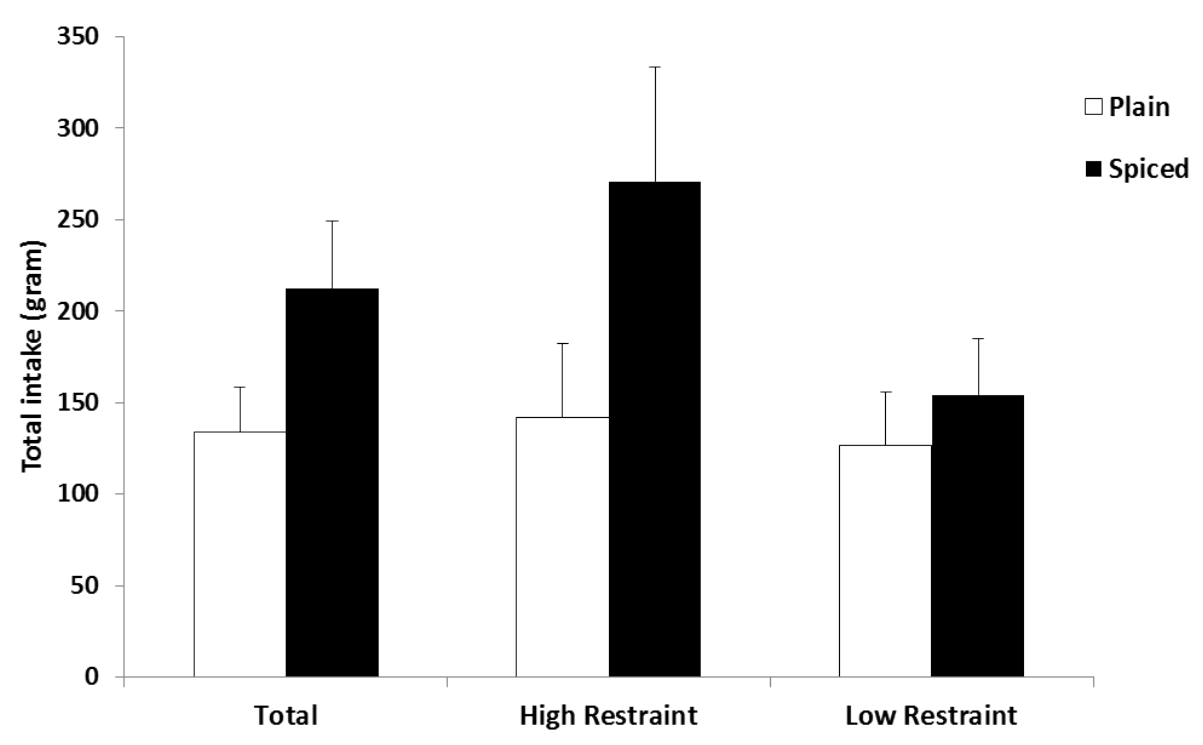

Figure 2. Total consumption of vegetables in high and low restraint eaters. $\square$ Plain vegetables without spice; $\mathbf{v}$ vegetables with spice.

ing that SSS secondary to the bitter taste of broccoli was reduced by the addition of spices to broccoli in restraint eaters.

Among the brassica vegetables, including broccoli and cauliflower, the levels of glucosinolates varies and is higher in broccoli than in cauliflower [21]. It is possible, but not proven, in our pilot study that the higher levels of glucosinolates in broccoli made it possible for us to see an effect with broccoli not seen with cauliflower. There are other known compounds in cruciferous vegetables which also contribute to their bitter taste. Furthermore, heating broccoli as we did in our study results in breakdown of glucosinolates, resulting in a decrease in bitter taste [22]. Consumers may not do this, which may also be affecting the results and needs to be considered in future studies.

Spinach is not part of the cruciferous family, but was studied due to the observation in young children that sensitivity to thioureas may predict reduced choosing of bitter-tasting spinach. Spinach is a member of the Chenopodiaceae family and the bitter-tasting leaves of this plant are particularly high in carotenoids, such as lutein and $\beta$-carotene, which are proven antioxidant agents [23]. In this study adding a mixture of spices to spinach did not lead to a significant increase in vegetable consumption or duration of eating.

Many studies have examined associations of psychosocial factors and dietary habits related to vegetable consumption [24] [25]. Individual and socio environmental factors during the developmental periods of children may influence adult dietary patterns as well [26]. The lack of information on frequency of the consumption of the 3 tested vegetables by our subjects prior to the study may have limited the capability of the study to detect any changes in cauliflower and spinach with and without spices. In addition, the subjects came from a diverse ethnic background and may have varied in their "typical" uses of spices in cooking.

\section{Conclusion}

Farmers have traditionally bred plants to optimize taste and appearance without consideration of their phytochemical content of fruits and vegetables. Future studies of the ability of spices to increase intake can be coupled with measurement of phytochemicals in vegetable and fruits to optimize the intake of phytochemicals with preventive potential while maintaining taste with added spices. While this pilot study was informative, more studies in greater numbers of subjects are needed to identify the specific effects of spices on taste perceptions and to determine the reasons for the lack of effects on spinach and cauliflower.

\section{Acknowledgements}

This study was supported by unrestricted Funds of the Department of Medicine of the David Geffen School of 
Medicine at UCLA. The authors report no conflicts of interest. The authors alone are responsible for the content and writing of the manuscript. All authors read and approved the final manuscript.

\section{References}

[1] Cooper, A.J., Sharp, S.J., Lentjes, M.A., et al. (2012) A Prospective Study of the Association between Quantity and Variety of Fruit and Vegetable Intake and Incident Type 2 Diabetes. Diabetes Care, 35, 1293-1300. http://dx.doi.org/10.2337/dc11-2388

[2] Ledoux, T.A., Hingle, M.D. and Baranowski, T. (2011) Relationship of Fruit and Vegetable Intake with Adiposity: A Systematic Review. Obesity Reviews, 12, e143-e150. http://dx.doi.org/10.1111/j.1467-789X.2010.00786.X

[3] Glanz, K., Basil, M., Maibach, E., Goldberg, J. and Snyder, D. (1998) Why Americans Eat What They Do: Taste, Nutrition, Cost, Convenience, and Weight Control Concerns as Influences on Food Consumption. Journal of the American Dietetic Association, 98, 1118-1126. http://dx.doi.org/10.1016/S0002-8223(98)00260-0

[4] Renner, B., Sproesser, G., Strohbach, S. and Schupp, H.T. (2012) Why We Eat What We Eat. The Eating Motivation Survey (TEMS). Appetite, 59, 117-128. http://dx.doi.org/10.1016/j.appet.2012.04.004

[5] Steptoe, A., Pollard, T.M. and Wardle, J. (1995) Development of a Measure of the Motives Underlying the Selection of Food: The Food Choice Questionnaire. Appetite, 25, 267-284. http://dx.doi.org/10.1006/appe.1995.0061

[6] Raghunathan, R., Naylor, R.W. and Hoyer, W.D. (2006) The Unhealthy = Tasty Intuition and Its Effects on Taste Inferences, Enjoyment, and Choice of Food Products. Journal of Marketing, 70, 170-184. http://dx.doi.org/10.1509/jmkg.70.4.170

[7] Kapusta-Duch, J., Kopeć, A., Piatkowska, E., Borczak, B. and Leszczyńska, T. (2012) The Beneficial Effects of Brassica Vegetables on Human Health. Roczniki Panstwowego Zakladu Higieny, 63, 389-395. Review.

[8] Drewnowski, A. and Gomez-Carneros, C. (2000) Bitter Taste, Phytonutrients, and the Consumer: A Review. The American Journal of Clinical Nutrition, 72, 1424-1435.

[9] Reed, D.R., Tanaka, T. and McDaniel, A.H. (2006) Diverse Tastes: Genetics of Sweet and Bitter Perception. Physiology \& Behavior, 88, 215-226. http://dx.doi.org/10.1016/j.physbeh.2006.05.033

[10] Mustonen, S., Hissa, I., Huotilainen, A., Miettinen, S.M. and Tuorila, H. (2007) Hedonic Responses as Predictors of Food Choice: Flexibility and Self-Prediction. Appetite, 49, 159-168. http://dx.doi.org/10.1016/j.appet.2007.01.005

[11] Schatzer, M., Rust, P. and Elmadfa, I. (2010) Fruit and Vegetable Intake in Austrian Adults: Intake Frequency, Serving Sizes, Reasons for and Barriers to Consumption, and Potential for Increasing Consumption. Public Health Nutrition, 13, 480-487. http://dx.doi.org/10.1017/S136898000999142X

[12] Drewnowski, A. (2001) The Science and Complexity of Bitter Taste. Nutrition Reviews, 59, 163-169. http://dx.doi.org/10.1111/j.1753-4887.2001.tb07007.x

[13] Birch, L.L. (1999) Development of Food Preferences. Annual Review of Nutrition, 19, 41-62. http://dx.doi.org/10.1146/annurev.nutr.19.1.41

[14] Ball, K., Crawford, D. and Mishra, G. (2006) Socio-Economic Inequalities in Women’s Fruit and Vegetable Intakes: A Multilevel Study of Individual, Social and Environmental Mediators. Public Health Nutrition, 9, 623-630. http://dx.doi.org/10.1079/PHN2005897

[15] Cappelleri, J.C., Bushmakin, A.G., Gerber, R.A., Leidy, N.K., Sexton, C.C., Lowe, M.R. and Karlsson, J. (2009) Psychometric Analysis of the Three-Factor Eating Questionnaire-R21: Results from a Large Diverse Sample of Obese and Non-Obese Participants. International Journal of Obesity, 33, 611-620. http://dx.doi.org/10.1038/ijo.2009.74

[16] Stunkard, A.J. and Messick, S. (1985) The Three-Factor Eating Questionnaire to Measure Dietary Restraint, Disinhibition and Hunger. Journal of Psychosomatic Research, 29, 71-83. http://dx.doi.org/10.1016/0022-3999(85)90010-8

[17] Dovey, T.M., Clark-Carter, D., Boyland, E.J. and Halford, J.C. (2009) A Guide to Analysing Universal Eating Monitor Data: Assessing the Impact of Different Analysis Techniques. Physiology \& Behavior, 96, 78-84. http://dx.doi.org/10.1016/j.physbeh.2008.08.016

[18] Abdull Razis, A.F. and Noor, N.M. (2013) Cruciferous Vegetables: Dietary Phytochemicals for Cancer Prevention. Asian Pacific Journal of Cancer Prevention, 14, 1565-1570. http://dx.doi.org/10.7314/APJCP.2013.14.3.1565

[19] Hu, F.B. (2003) Plant-Based Foods and Prevention of Cardiovascular Disease: An Overview. American Journal of Clinical Nutrition, 78, 544S-551S.

Kapusta-Duch, J., Kopec, A., Piatkowska, E., Borczak, B. and Leszczynska, T. (20120) The Beneficial Effects of Brassica Vegetables on Human Health. Roczniki Państwowego Zakładu Higieny, 63, 389-395.

[20] Meillon, S., Thomas, A., Havermans, R., Penicaud, L. and Brondel, L. (2013) Sensory-Specific Satiety for a Food Is Unaffected by the Ad libitum Intake of Other Foods during a Meal. Is SSS Subject to Dishabituation? Appetite, 63, 
112-118. http://dx.doi.org/10.1016/j.appet.2012.12.004

[21] Kushad, M.M., Brown, A.F., Kurilich, A.C., Juvik, J.A., Klein, B.P., Wallig, M.A. and Jeffery, E.H. (1999) Variation of Glucosinolates in Vegetable Crops of Brassica oleracea. Journal of Agricultural and Food Chemistry, 47, 15411548. http://dx.doi.org/10.1021/jf980985s

[22] Fenwick, G.R., Heaney, R.K., Mullin, W.J. and VanEtten, C.H. (1983) Glucosinolates and Their Breakdown Products in Food and Food Plants. C R C Critical Reviews in Food Science and Nutrition, 18, 123-201. http://dx.doi.org/10.1080/10408398209527361

[23] Britton, G. (1995) Structure and Properties of Carotenoids in Relation to Function. FASEB Journal, 9, 1551-1558.

[24] Satia, J.A., Kristal, A.R., Patterson, R.E., Neuhouser, M.L. and Trudeau, E. (2002) Psychosocial Factors and Dietary Habits Associated with Vegetable Consumption. Nutrition, 18, 247-254. http://dx.doi.org/10.1016/S0899-9007(01)00758-4

[25] Van Duyn, M.A., Kristal, A.R., Dodd, K., Campbell, M.K., Subar, A.F., Stables, G., et al. (2001) Association of Awareness, Intrapersonal and Interpersonal Factors, and Stage of Dietary Change with Fruit and Vegetable Consumption: A National Survey. American Journal of Health Promotion, 16, 69-78. http://dx.doi.org/10.4278/0890-1171-16.2.69

[26] Krolner, R., Rasmussen, M., Brug, J., Klepp, K.I., Wind, M. and Due, P. (2011) Determinants of Fruit and Vegetable Consumption among Children and Adolescents: A Review of the Literature. Part II: Qualitative Studies. International Journal of Behavioral Nutrition and Physical Activity, 8, 112. http://dx.doi.org/10.1186/1479-5868-8-112 